\title{
Evaluation of Relative Blood Viscosity During Menstruation in Reproductive Females
}

\author{
${ }^{*}$ F.O. Agoreyo and C. Okorie \\ Department of Physiology, School of Basic Medical Sciences, College of Medical Sciences, University of Benin, Benin City, Edo \\ State. Nigeria \\ [Corresponding Author: Email: agoreyofo@yahoo.com; $\mathbf{8}:+2348035628857]$
}

\begin{abstract}
The changes in blood viscosity, plasma viscosity, haematocrit and erythrocyte sedimentation rate before and during menstruation were evaluated. Forty (40) apparently healthy reproductive female subjects (between 15 and 28 years) and resident in Benin City, Edo State, Nigeria were used for the study. The parameters were analyzed using standard laboratory procedures and the data obtained were subjected to statistical analysis (paired t-Test; correlation and regression). Blood samples were collected during two phases of the menstrual cycle - the premenstrual and the mid menstrual phase. Results show variations in the studied parameters before and during menstruation. Relative blood viscosity, relative plasma viscosity and hematocrit were significantly reduced $(P<0.001)$ during menstruation compared to the values before menstruation. The mean values of relative blood viscosity, relative plasma viscosity and hematocrit were $2.52 \pm 0.07,1.15 \pm 0.01$ and $0.37 \pm 0.004 \mathrm{~L} / \mathrm{L}$ respectively for menstrual phase and $3.86 \pm 0.07,1.49 \pm 0.02$, $0.43 \pm 0.005 \mathrm{~L} / \mathrm{L}$ respectively for premenstrual phase. Erythrocyte sedimentation rate (ESR) was significantly higher $(6.78 \pm 0.18 \mathrm{~mm} / \mathrm{hr})$ during the menstrual phase than during the premenstrual phase $(4.61 \pm 0.10 \mathrm{~mm} / \mathrm{hr})$ at $P<0.001$. Blood viscosity thus decreases during menstruation and this may be reduce the risk of cardiovascular diseases in premenopausal women.
\end{abstract}

Keywords: Menstruation, Relative blood viscosity, Relative plasma viscosity

\section{INTRODUCTION}

Blood viscosity is a measurement of the thickness and stickiness of a person's blood. Blood viscosity is a measure of the ability of blood to resist gradual deformation by shear or tensile stresses thereby leading to a resistance of blood to flow (Baskurt and Meiselman, 2003). Factors that affect blood viscosity includes; plasma viscosity, hematocrit, erythrocyte deformability, erythrocyte aggregation, and temperature. Menstruation is simply the periodic discharge of blood and mucosal tissue from the inner lining of the uterus through the vagina. This cyclic discharge is seen in females of certain mammalian species (including humans). It begins with the onset of menarche at or before sexual maturity and stops at or near menopause (commonly considered the end of a female's reproductive life). The periodicity of menstruation gives rise to commonly used euphemisms such as "period" and "monthly" (Logan and Carolyn, 1997). Profound physiologic changes occur in females during the monthly menstrual cycle. These include changes in blood pressure, variations in hematocrit, cyclic changes in thrombocyte count and white cell count. These changes are due to the effect of the female sex hormones: oestrogens and progesterone and the pituitary gonadotropins. These reported variations of vascular and hematologic parameters could possibly influence blood viscosity. Studies on haemorheological changes in black Africans are relatively scarce; this is especially with regard to changes during the menstrual cycle. Such studies are important to fully understand the possible role blood viscosity changes play in determining reported changes in blood pressure during the menstrual cycle (Reid andAnah, 1985).

\section{MATERIALS AND METHODS}

Subjects: A total of forty (40) females aged between 15 and 28 years with normal body mass index (BMI) were recruited into the study. They were selected by systematic random sampling from the female student population of about 400 at Simplex Academy lecture centre at Agbor park area, Benin City, Edo State, Nigeria. Each student gave informed consent and none had antecedent 
history of cardiovascular or neurologic disease or condition. Cases of irregular periods, chronic disease and with history of drug affecting the menstrual cycle were not included. Inclusion criterias includes females who had no cardiovascular disease or any other condition and only subjects with a normal menstruation cycles of $30 \pm 3$ days were recruited. They were physically examined and found apparently healthy. The forty healthy females were divided into two groups; premenstrual phase or Luteal phase which includes those expecting their "period" or menses and Menstrual phase $\left(2^{\text {nd }}-4^{\text {th }}\right.$ day) which include those already menstruating.

\section{Blood Collection}

Each subject was allowed to rest comfortably for at least 20 minutes before blood collection. Five milliliters $(5 \mathrm{mls})$ of blood were collected using a hypodermal syringe from an antecubital vein with the subject comfortably seated and with minimum stasis. Blood sample was collected during the luteal phase (middle of luteal phase) and during menstruation. The blood was immediately transferred into an EDTA container. An aliquot of 20ul from this sample was used for the determination of hematocrit. One milliliter was used for the measurement of relative whole blood viscosity, $2 \mathrm{ml}$ were used for erythrocyte sedimentation rate (ESR) determination and the remainder was centrifuged at 3000rpm for five minutes. The plasma was separated and used for the measurement of relative plasma viscosity. All specimens were analyzed within three hours of collection to avoid diurnal variation.

\section{Methods}

Relative blood viscosity and relative plasma viscosity was determined by capillary viscometry using the single syringe method first described by Reid and Ugwu (1987) and modified by koroboOwiye et al., (1997). Hematocrit was determined by the microhematocrit technique which involves the use of microcapillary tubes (Ochei and Kolhatkar, 2000). Erythrocyte Sedimentation Rate (ESR) was estimated by the method of Westergren (Dacie and Lewis, 1991).

\section{Statistical Analysis}

All values were expressed in mean \pm standard error of mean. Data were analyzed using unpaired $t$-Test at $p<0.001$. Correlation and regression analysis was also done to show the relationship between the determinants of blood viscosity and plasma viscosity. Microsoft excel office package and SPSS were used.

\section{RESULTS AND DISCUSSION}

Table 1: Values of relative blood viscosity and its selected determinants during Premenstrual and Menstrual phases in women in Benin-city, Nigeria.

\begin{tabular}{llll}
\hline Parameters & $\begin{array}{l}\text { Menstrual } \\
\text { phase }(\mathrm{n}=20)\end{array}$ & $\begin{array}{l}\text { Premenstrual } \\
\text { phase } \\
(\mathrm{n}=20)(\text { control) }\end{array}$ & $\begin{array}{l}\text { Significance } \\
\text { (student's } \\
\text { unpaired T- } \\
\text { test) }\end{array}$ \\
\hline Relative Blood Viscosity & $2.52 \pm 0.07$ & $3.86 \pm 0.07$ & $(\mathrm{p}<0.001)$ \\
$\begin{array}{l}\text { Relative Plasma Viscosity } \\
\text { Haematocrit (L/L) }\end{array}$ & $1.15 \pm 0.01$ & $1.49 \pm 0.02$ & $(\mathrm{p}<0.001)$ \\
$\begin{array}{l}\text { Erythrocyte sedimentation rate } \\
(\mathrm{mm} / \mathrm{hr})\end{array}$ & $0.37 \pm 0.004$ & $0.43 \pm 0.005$ & $(\mathrm{p}<0.001)$ \\
\hline
\end{tabular}


Nigerian Journal of Basic and Applied Science (December, 2016), 24(2): 60-65

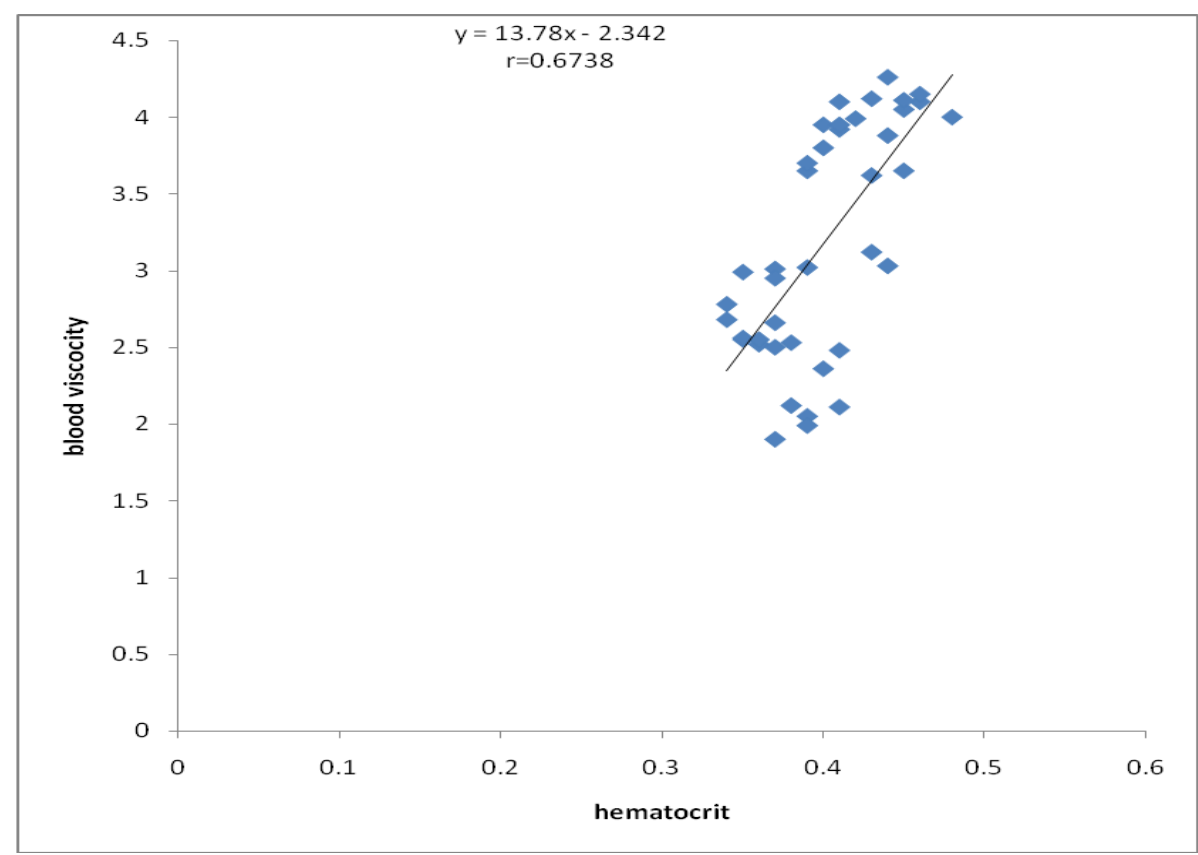

Figure 1 Regression analysis graph of blood viscosity and hematocrit during the menstrual phase $(p<0.001)$

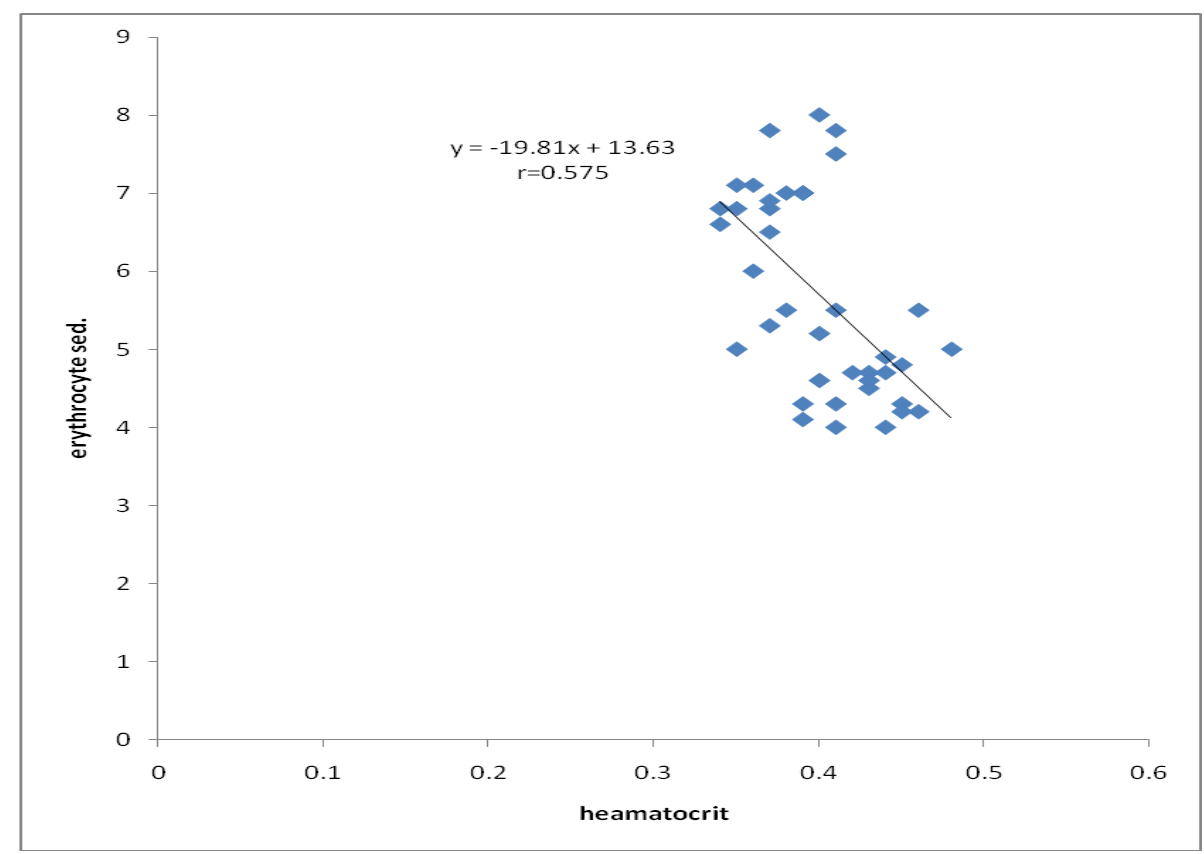

Figure 2: Regression analysis graph between erythrocyte sedimentation rate and haematocrit $(p<0.001)$. 


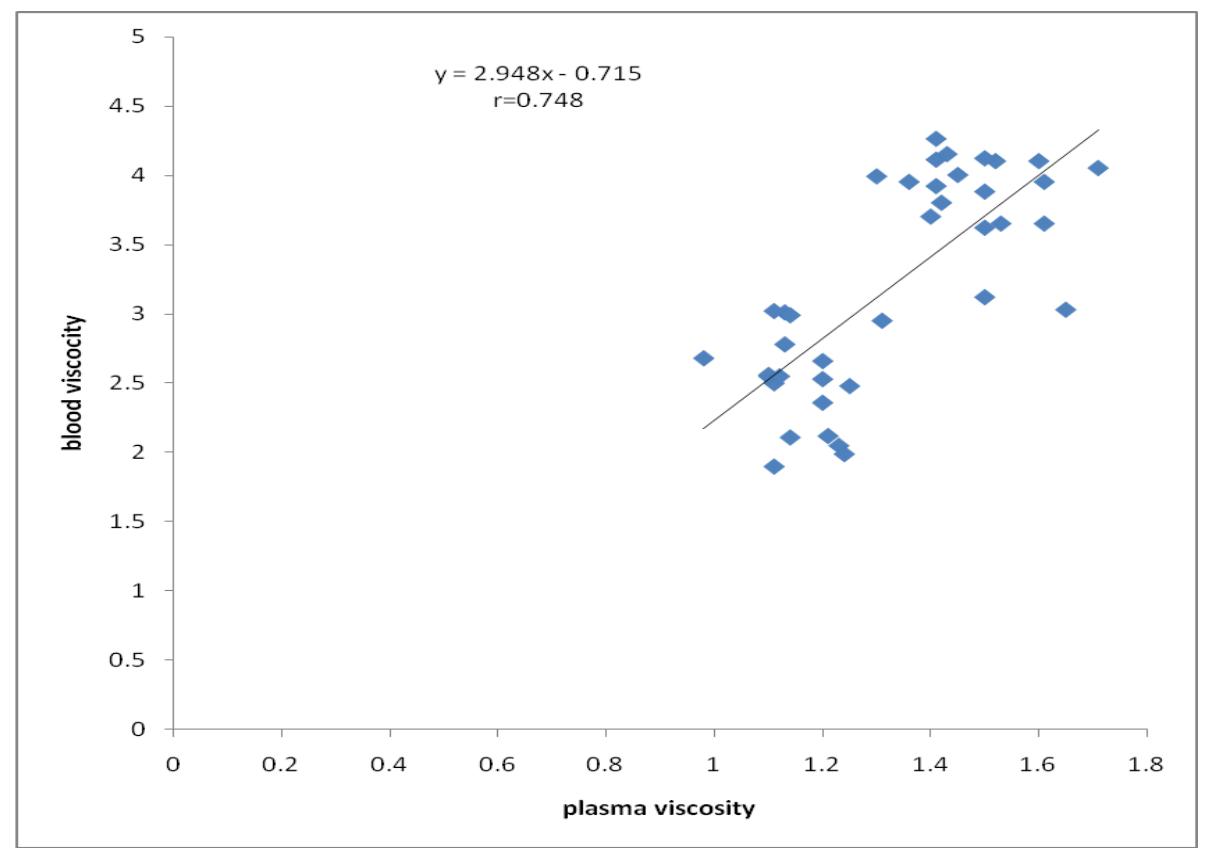

Figure 3: Regression analysis graph between blood viscosity and plasma viscosity during menstrual phase $(p<0.001)$.

The results of the present study (Table 1) clearly indicate that blood viscosity and its determinants show significant $(p<0.001)$ changes during the menstrual phase and premenstrual phase of the menstrual cycle. Interplay of several factors including the effect of menstruation and of the female sex hormones could possibly account for these changes in blood viscosity and its determinants. The results of this study have shown that some haemorheological profiles are altered at different phases of menstrual cycle. Hence, the present findings are in line with the report by Malini (2006), who studied haemorheological profiles in different phases of menstrual cycle in Bangalore, India. Low hematocrit values reported during the menstrual phase is likely due to blood loss that occurs at this phase of the cycle, leading to a reduction in red cell population. Low hematocrit during this phase is not fully explained by blood loss alone. Perhaps, changes in the concentration of hormones: oestrogen and progesterone during the menstrual cycle could contribute. There is usually a sudden drop in the levels of these female hormones during menstruation (Chiazzeet al., 1968). One of the functions of estrogen and progesterone is to maintain constant flow of blood to the uterus since they are vasodilators. It has been reported that estrogen promotes vasodilatation by stimulating the release of prostacyclin and nitric oxide and inhibiting the production of vasoconstrictors like Angiostensin II and endothelins (Rajnee et al., 2010). A decrease in estrogen will thus decrease the constant flow of blood which leads to the rupture of the blood vessels and subsequent loss of blood from the body. Loss of blood will lead to a decrease in hematocrit (Speroh and Vande, 1971).

The relative whole blood viscosity (RWBV) showed a trend similar to that of hematocrit (Hct), being higher at the premenstrual phase and lower at the menstrual phase. Though several interdependent factors largely influence blood viscosity, hematocrit plays a primary role. Figure 1 shows a highly significant $(r=0.67 ; p<0.000001)$ regression between blood viscosity and hematocrit. Blood viscosity regresses strongly on 
hematocrit and it is thus a dependent variable. It therefore means that blood viscosity would largely decrease and increase along with hematocrit (Dacie and Lewis, 1991). A reduction in blood viscosity means increase blood flow through the body circulation, and this reduces the risk of hypertension. Premenopausal women have been reported to have a lower risk and incidence of hypertension and cardiovascular disease (CVD) compared to age-matched men and that this sex advantage for women gradually disappears after menopause, suggesting that sexual hormones play a cardio-protective role in women (Yang and Reckelhoff, 2011).

The increase in erythrocyte sedimentation rate (ESR) in the menstrual phase is in line with the studies by Malini (2006) that ESR will fall faster due to decrease in hematocrit. Report by Dacie and Lewis, (1991) shows that polycythemic subjects will naturally have low ESR due to increase in erythrocyte aggregation (which forms a rouleaux) and reduced erythrocyte deformability which causes a slow fall in red blood cells. The regression analysis graph of Figure 2 shows a high significant regression $(r=0.575 ; p<0.0001)$ between erythrocyte sedimentation rate and hematocrit. It is clear from the graph that ESR regresses inversely on hematocrit which means that ESR will likely decrease as hematocrit increases and vice versa. Thus, decrease in hematocrit could possibly account for the faster fall of red blood cells and hence increased ESR observed during menstruation (Everett et al., 1978). Increase ESR during the menstrual phase could possibly explain decrease blood viscosity observed at this phase (Cheesbrough, 2000).

Plasma viscosity was higher in premenstrual phase and lower in menstrual phase. The observed reduction in plasma viscosity is in line with the report by Kim et al. (1993) that mean values of hemoglobin, transferrin saturation and serum transferrin, were lowest during menses and highest in luteal or late luteal phase. Low transferrin can impair hemoglobin production since iron is needed to make hemoglobin (Crichton and
Charloteaux-Wauters, 1987). It thus means that a low level of transferrin could lead to low level of hemoglobin which could result in decreased plasma viscosity observed during the menstrual phase (Macedo and De souse, 2008). Figure 3 shows a very high significant $(r=0.748 ; p<$ 0.00000001 ) regression of blood viscosity on plasma viscosity. Menstrual fluid which flows out of a reproductive female is composed of blood, old parts of uterine tissue, cells, mucin, bacteria making up the vagina flora, vagina secretions which contain water, and electrolytes such as sodium and potassium (Lentonet al., 1984). It also contains iron (fibrinogen), hemoglobin, proteins, platelets, cholesterol and bilirubin. Most of these substances are found in the blood plasma. It could thus be said that a loss in these substances from the plasma will help to keep plasma viscosity down. A decrease in relative plasma viscosity will likely explain the decrease in whole blood relative viscosity observed during the menstrual phase (Baker et al., 2001).

\section{CONCLUSION}

Since relative whole blood viscosity is lower during the menstrual phase and higher during the premenstrual phase of the menstrual cycle, it can thus be concluded that blood viscosity thus decreases during menstruation and this may be reduce the risk of cardiovascular diseases in premenopausal women.

\section{REFERENCES}

Baker, F.J., Silverton, R.E. and Pallister, C.J. (2001).The full blood counthaematology. In: Introduction to Medical Laboratory Technology. $7^{\text {th }}$ Ed. Reed Elsevier. Pp. 337 - 384.

Baskurt, O.K. and Meiselman, H.J. (2003). Blood rheology and hemodynamics. Seminars in Thrombosis and Haemostasis, 29: 435-450.

Chiazze, L., Brayer, F.T., Macisco, J.J., Parker, M.P. and Duffy B.J. (1968).The length and variability of the human menstrual cycle. JAMA, 203(6): 377-80. 
Cheesbrough, M. (2000). Haematological test. In: District laboratory practice in tropical countries. Part 2.Cambridge University Press. London. Pp. 267 - 347.

Crichton, R.R. and Charloteaux-wauters, M. (1987). Iron transport storage. European Journal of Biochemistry, 164 (3): 485-506.

Dacie, J.V. and Lewis, S.M. (1991).Practical Haematology. $7^{\text {th }}$ Ed. Churchill Livingstone, Edinburgh. Pp. 521-534.

Everett, R.B., Worley, R.J., MacDonald, P.C. and Gant, N.F. (1978). Modification of vascular responsiveness to Angiotensin -II in pregnant women by intravenously infused 5 alpha dihydroprogesterone. American Journal of Obstetrics and Gynecology, 131:352-357.

Kim, I., Yetley, E.A. and Calvo, M.S. (1993).Variations in iron status measures during the menstrual cycle,. The American Journal of Clinical Nutrition, 58: 705 - 709.

Korubo-Owiye, T., Dapper D.V. and Emakpor, A.C. (1997).The Effect of Cigarette smoking on some haemorheological parameters. Nigerian Medical Practitioner, 33:52-55.

Lenton, E.A., Landgren, B.M. and Sexton, L. (1984).Normal variation in the length of the luteal phase of the menstrual cycle: identification of the short luteal phase. Br. J. Obstet. Gynaecol., 91(7): 685690.

Logan, P. and Carolyn, C.(1997).Take Your Choice. Counterbalance: Gendered
Perspectives on Writing and Language. Pp. 41.

Macedo, M.F. and De souse, M. (2008). Transferrin and the transferring receptor: of magic bullets and other concerns. Inflammation and Allergy Drug Targets, 7(1): 41-52.

Malini, K. (2006). Haematological profile of different phases of menstrual cycle.PhD thesis.Rajiv Gandhi University of Health Sciences. Karnataka, Bangalore.

Ochei, O.J. and Kolhatkar, A.A. (2000).Medical Laboratory Science Textbook.6 $6^{\text {th Ed. }}$. McGraw -Hill publishers.Pp282-284

Rajnee, V.K., Raghuveer, C., Bijendra, K.B. and Sunita, C. (2010). Haematological and electrocardiographic variations during menstrual cycle. Pakistan Journal of Physiology, 6(1): 18 - 21.

Reid, H.C. and Anah C.O. (1985).Haemorheological parameters in hypertensive Nigerians with and without sickle cell trait. Angiology, 36:379-386.

Reid, H.L. and Ugwu, C.A.(1987). A simple technique for rapid determination of plasma viscosity. Nigerian Journal of Physiological Sciences, 3:45-48.

Speroh, L. and Vande, W.R.L. (1971).Regulations of the human menstrual cycle. American Journal of Obstetrics and Gynecology, 109: 234-238.

Yang, Z.P. and Reckelhoff, J.F. (2011). Estrogen, hormonal replacement therapy and cardiovascular disease. Current Opinion in Nephrology and Hypertension, 20(2): 133-138. 